\title{
O MODELO DO ESTADO DESENVOLVIMENTISTA JAPONÊS: ASPECTOS HISTÓRICOS E CONSIDERAÇÕES SOBRE SUA RELEVÂNCIA NO MUNDO CONTEMPORÂNEO
}

\author{
THE JAPANESE DEVELOPMENTAL STATE MODEL: HISTORICAL ASPECTS AND \\ CONSIDERATIONS ON ITS RELEVANCE IN THE CONTEMPORARY WORLD
}

\author{
Waldemiro Francisco Sorte Junior \\ Ministério da Economia, DF, Brasil \\ E-mail:waldrusso@gmail.com
}

Recebido em: 20.09.2019 - Aceito em: 24.11.2019

DOI: http://dx.doi.org/10.5902/2526629240096

RESUMO: O presente trabalho realiza uma revisão bibliográfica voltada a definir os principais elementos do estilo de intervenção estatal na economia implementado pelo Japão durante o período pós-guerra, conhecido como modelo do Estado desenvolvimentista, que resultou em altos níveis de crescimento industrial e econômico, sobretudo nas décadas de 1970 e 1980. As discussões realizadas sobre o modelo em questão centram-se na indústria automobilística japonesa, uma vez que funciona como um exemplo de como a intervenção do Estado no setor privado resultou no fortalecimento de montadoras e de fornecedores locais a ponto de atingirem níveis elevados de produtividade, qualidade e competitividade na esfera internacional. Por fim, este artigo realiza considerações sobre aspectos exógenos ao modelo do Estado desenvolvimentista que também contribuíram para o seu sucesso no período pós-guerra e analisa se tal modelo ainda possui aplicabilidade ao mundo globalizado atual.

PALAVRAS-CHAVE: Intervenção do Estado na economia; políticas públicas; modelo do Estado desenvolvimentista; crescimento econômico; Japão.

ABSTRACT: This study is based on a literature review focused on identifying the key elements of the style of state intervention in the economy implemented by Japan during the postwar period, the so-called Developmental State Model, which resulted in high levels of economic and industrial growth, especially during the 1970 s and 1980s. The discussions about the model are centered on the Japanese automobile industry, as this sector is an example of how state intervention in the private sector strengthened domestic automakers and suppliers, enabling them to achieve high levels of productivity, quality and competitiveness at the international 
level. Finally, this article also presents exogenous elements that contributed for the success of the Developmental State Model during the postwar period and examines whether this model is still applicable in today's globalized world.

KEYWORDS: State Intervention in the Economy; Public Policy; Developmental State Model; Economic Growth; Japan.

\section{INTRODUÇÃO}

Este trabalho examina o estilo de intervenção do Estado na economia praticado pelo Japão no período pós-guerra, procurando definir os principais elementos responsáveis pelos seus resultados positivos em termos de desenvolvimento econômico. Diversos autores (Johnson, 1983; Pempel, 1999b; Wade, 1990; Sorte, 2011) destacam o papel fundamental exercido pelo governo japonês no rápido crescimento econômico e industrial observado no país, sobretudo nas décadas de 1970 e 1980. O presente estudo se destina a examinar o referido modelo, abordando suas principais vantagens e discutindo se ainda é aplicável ao mundo globalizado atual.

O Japão possui uma longa história de relacionamento colaborativo entre os setores público e privado visando ao alcance do desenvolvimento econômico. Os altos índices de crescimento observados no país nas décadas de 1970 e 1980 foram o resultado de políticas industriais focadas no estímulo de setores industriais considerados estratégicos para promover o dinamismo industrial (Johnson, 1983). Dessa forma, a abordagem japonesa de intervencionismo estatal é caracterizada pela iniciativa do governo em selecionar setores industriais estratégicos e estabelecer políticas, em conjunto com o setor privado, capazes de fomentar o crescimento de empresas domésticas nesses segmentos industriais específicos. Em razão dos resultados positivos alcançados pelo Japão no período pós-guerra, o presente estudo examina a utilidade da adoção dessa experiência japonesa como um modelo de referência para políticas industriais em países em desenvolvimento na atualidade.

Embora o conceito de desenvolvimentismo tenha surgido em momento anterior da história, o estilo de intervenção do Estado na economia do Japão no período pós-guerra ficou conhecido, a partir de estudos sobre a atuação do Ministério do Comércio Internacional e Indústria (Tsūshōsangyō-shō 通商産業省, doravante denominado MITI) realizados inicialmente por Johnson (1983), especificamente como o modelo do Estado desenvolvimentista (Perissinotto, 2014, p. 61; Bresser-Pereira, 2018, p. 865). 
Conforme assinala Cunha (2012, 291-292), especialmente em função do crescimento de diversos países emergentes como a China e da crise financeira internacional de 2007-2008, que gerou uma perda de credibilidade quanto à eficiência do neoliberalismo, diversos estudos nas últimas décadas voltaram a se dedicar ao exame do papel do Estado na promoção do desenvolvimento socioeconômico e na elaboração de políticas industriais capazes de criar maior dinamismo e crescimento econômico. Temas relacionados a políticas industriais, que caíram em descrédito tanto em debates no meio acadêmico quanto em discussões de gestores de políticas públicas a partir da década de 1970 com o advento do neoliberalismo, voltaram a ganhar espaço e força a partir da metade da década de 2000, sobretudo em função dos efeitos da crise (Andreoni \& Chang, 2019, p. 136).

O retorno de tópicos relacionados à intervenção do Estado na economia e à relevância de políticas públicas para a promoção do desenvolvimento muitas vezes confluíram para um esforço de revisitar o modelo desenvolvimentista utilizado pelo Japão no período pós-guerra e por outros países do leste asiático. No âmbito desse modelo, a atuação do Estado transcende a mera regulação do mercado e torna-se central na evolução da estrutura econômica, utilizando-se da política industrial para promover a "transformação estrutural e capacidade competitiva em âmbito interno e internacional" (Pereira \& Dathein, 2016, p. 33-34).

Cumpre destacar que, apesar de reconhecer a existência de parcela da literatura acadêmica que se opõe à intervenção do Estado na economia, a apresentação e discussão dos argumentos em prol e contra o intervencionismo não constitui o escopo do presente artigo. Adota-se o posicionamento de que a intervenção do Estado, sob a forma de políticas públicas e industriais, constitui uma realidade no mundo atual, razão pela qual a identificação de modelos e medidas mais adequadas a determinado ambiente político-econômico parece possuir vantagens empíricas mais relevantes do que debates teóricos sobre a necessidade ou não da intervenção estatal em si.

O presente estudo é baseado em um exame de fontes secundárias para a definição das principais características do modelo do Estado desenvolvimentista. A literatura acadêmica nessa área, vale ressaltar, é extensa, dado o desenvolvimento econômico observado no Japão no período pós-guerra e o crescimento de diversas empresas locais, tais como Toyota, Nissan e Mitsubishi, que se tornaram transnacionais de destaque na esfera mundial. Adota-se uma abordagem conceitual dos elementos responsáveis pelo alto desempenho do referido modelo, uma vez que se examina a forma de intervenção estatal implementada pelo Japão no 
período pós-guerra e seus resultados econômicos, bem como outras variáveis exógenas que, durante a história do país, concorreram para o alcance de resultados positivos no desenvolvimento japonês.

Este artigo encontra-se dividido em quatro seções, incluindo esta introdução. A próxima seção realiza uma análise dos principais elementos responsáveis pelos resultados positivos observados no período pós-guerra japonês, que são conhecidos como o modelo do Estado desenvolvimentista. A seção três discute se o modelo em questão ainda possui aplicabilidade frente às mudanças da economia mundial contemporânea. A quarta seção conclui o estudo.

\section{O PADRÃO INTERVENCIONISTA JAPONÊS NO PERÍODO PÓS-GUERRA: O MODELO DO ESTADO DESENVOLVIMENTISTA}

O Japão possui uma longa história de parcerias entre os setores público e privado para a promoção do crescimento econômico. Os altos índices de crescimento econômico observados no país, sobretudo durante as décadas de 1970 e 1980, foram resultados de políticas industriais focadas em setores considerados estratégicos, seja em função de sua importância na promoção de um maior dinamismo industrial, seja pelo seu potencial de gerar externalidades e spillovers (Johnson, 1983; Evans, 1995). Dore (2000, p. 44) assevera que a burocracia estatal japonesa desempenhou um forte papel regulatório no mercado, por intermédio da ampla utilização de recomendações governamentais, denominadas em japonês de gyōsei shidō (行政指導). Esse mecanismo foi vastamente utilizado pela administração pública japonesa como um tipo de recomendação ou aconselhamento que, apesar de informal, era rapidamente obedecido pelo setor privado (Haley, 1991; Sorte, 2014, p. 227). Na verdade, estudos do período Meiji (1868-1912) já mostram o forte intervencionismo do Estado japonês no país, revelando que o capitalismo no país desenvolveu-se sob a proteção e o subsídio do Estado (Norman, 2000, p. 111).

O governo japonês utilizou diversos mecanismos para estimular o crescimento de empresas locais, tais como barreiras tarifárias e políticas de promoção à exportação. Nesse sentido, portanto, observa-se a importância da existência de uma administração pública composta por servidores tecnicamente competentes e recrutados por procedimentos específicos, de forma a criar uma burocracia estatal bem ordenada, "portadora de um ethos burocrático e de um acentuado esprit de corps e protegida de pressões clientelistas" (Perissinotto, 2014, p. 62).

Assim, a intervenção do Estado japonês no período pós-guerra centrou-se em selecionar setores industriais capazes de gerar crescimento econômico e em fomentar empresas e empreendedores nacionais para que aumentassem 
progressivamente a produção e qualidade de seus produtos. Esse processo foi marcado por intensa e constante troca de informações e negociações entre o governo e o setor privado e pelo uso de políticas voltadas ao atendimento das necessidades das empresas domésticas.

Assim, pode-se dizer que o padrão de relacionamento entre os setores público e privado no Japão é tradicionalmente baseado em trocas constantes e intensas de informações com o propósito de atingir objetivos mútuos. A intervenção do Estado japonês na economia é caracterizada por um processo contínuo de negociação e cooperação com empresas domésticas visando à promoção do desenvolvimento de setores industriais estratégicos. Esse padrão de intervenção ficou conhecido na literatura acadêmica como o modelo do Estado desenvolvimentista (Sorte, 2011).

Na verdade, muitos autores defendem que o modelo do Estado desenvolvimentista foi fundamental não apenas para a prosperidade econômica do Japão, mas também de outros países do leste asiático, sobretudo Taiwan e Coreia do Sul (Amsden, 1989; Wade, 1990; Kohli, 1999). Nesse modelo, o governo é capaz de desenvolver um projeto contínuo de incremento produtivo, sofisticação tecnológica e ampliação progressiva da participação de empresas domésticas no mercado global (Pempel, 1999b, p. 139).

A parceria entre os setores público e privado no Japão está implícita na discussão de Johnson (1983, p. 317-318) sobre o papel do governo japonês na promoção do crescimento industrial no período pós-guerra. Esse tipo de relação foi criado por intermédio de um processo de interação que se desenvolveu no decorrer da história do país, muitas vezes resultando em conflitos. Por exemplo, durante o fim da década de 1940 havia uma dominância do Estado, enquanto que no início da década de 1970 eram as empresas privadas que tinham maior força. Isso demonstra que a cooperação no Japão foi um processo construído ao longo dos anos, resultante de constantes negociações e aprendizagem por tentativa e erro. Havia intercâmbio contínuo de informações entre a administração pública e as empresas japonesas, a fim de que as necessidades dos empreendedores pudessem ser supridas e fossem criadas condições para o crescimento industrial.

Evans (1995) descreve esse tipo de relacionamento entre setores público e privado no Japão com o termo "autonomia inserida" (em inglês, embedded autonomy). O conceito de inserção (embeddedness) implica na necessidade de imersão do governo no setor privado, de forma a entender as necessidades mais fundamentais e urgentes das empresas. Foi por meio desse engajamento próximo com o setor privado que o governo japonês conseguiu desempenhar um papel efetivo na regulação do mercado e na promoção do crescimento industrial. Essa interação também facilita o processo de adaptar e corrigir eventuais deficiências em políticas 
públicas, de modo a permitir que os resultados almejados sejam de fato atingidos.

Evans (1995), entretanto, acrescenta que, apesar da necessidade de inserção no setor privado, o governo também precisa de autonomia, como forma de proteger-se da corrupção e resistir a pressões políticas. Dessa maneira, o setor público será capaz de definir políticas que possam alcançar os principais objetivos da nação, sem curvar-se a interesses privados. Para o êxito dessa "autonomia inserida", cumpre acrescentar que é importante a existência na sociedade de grupos razoavelmente estruturados e organizados para se tornarem interlocutores do governo e construírem conjuntamente a agenda do desenvolvimento. Assim, um contexto social marcado por uma alta fragmentação poderia ser considerado um empecilho ao avanço do Estado desenvolvimentista (Perissinotto, 2014, p. 62).

Nesse contexto, é importante frisar o papel desempenhado pelo MITI no planejamento do desenvolvimento industrial japonês durante o período pós-guerra. $\mathrm{O}$ MITI foi capaz de selecionar os setores industriais que poderiam levar o país rumo a níveis elevados de crescimento econômico e convencer empresas privadas japonesas a adentrarem nesses setores. Wade (1990, p. 335) descreve da seguinte forma os passos mediante os quais o MITI identificava setores industriais estratégicos:

Primeiro, os servidores do MITI estudavam a elasticidade-renda da demanda para vários itens nos principais mercados do mundo, especialmente nos Estados Unidos. Segundo, eles examinavam as tendências em mudança tecnológica em diversas indústrias. Terceiro, eles analisavam indústrias com alta elasticidade-renda e alto potencial para mudanças tecnológicas, contrastando com o índice de especialização do Japão, ou a participação de cada indústria nas exportações industriais japonesas em relação à participação das indústrias no comércio mundial (...). Quarto, essas autoridades públicas verificavam as tendências em relação a um outro índice, denominado 'coeficiente de separação da exportação e indústria', que media a relação entre a importância de determinado item no total da produção japonesa em relação a sua relevância frente às exportações (...). De posse de tais medidas, o governo conseguia identificar em quais setores deveria intervir para estimular melhor desempenho em termos de produtividade e exportação (Wade, 1990, p. 335, tradução nossa).

O papel do MITI não se restringiu à identificação de setores estratégicos para promover o dinamismo industrial e crescimento econômico. Ele também atuou de forma plena e ativa no setor privado, estimulando o investimento de empresas japonesas em setores industriais estratégicos. Desenvolveu também uma série de políticas visando atender às principais necessidades dessas empresas.

No caso específico da indústria automotiva, a intervenção do MITI foi relevante para estimular o crescimento das montadoras japonesas. Durante o perío- 
do compreendido entre 1945 e 1952, que corresponde à ocupação dos Estados Unidos no Japão, restrições de importações foram suspensas em razão da baixa produção doméstica, o que acarretou no crescimento da importação de veículos estrangeiros, com consequente impacto negativo na balança de pagamentos do país. Para solucionar esse problema, com o fim do período da ocupação, o MITI impôs um imposto sobre o valor agregado (IVA) de 40\% na importação de veículos, resultando na redução de importações de 44,6\% em 1952 para 8,9\% em 1955, além de adotar outras medidas visando à melhoria dos automóveis produzidos no país (Cusumano, 1985, p. 7-8).

O MITI estimulou, por intermédio de políticas públicas, a transferência de conhecimento e tecnologia de firmas estrangeiras para as montadoras japonesas no que tange à produção de carros pequenos. Antes da Segunda Guerra Mundial, a experiência das montadoras japonesas restringia-se à manufatura de caminhões. $\mathrm{O}$ MITI, entretanto, esperava um crescimento na demanda de veículos pequenos no período pós-guerra e, a partir de 1952, o governo incentivou as montadoras japonesas a realizarem negociações com empresas europeias para produzirem no Japão, pelo período de três ou quatro anos, veículos com componentes pré-montados importados (chamados em inglês de completely knock-down kits ou CKD). O principal objetivo era fomentar uma gradual transferência de tecnologia das empresas europeias para as japonesas, que resultaria na progressiva diminuição do uso de componentes importados e consequente aumento da utilização de partes produzidas no Japão.

O MITI esperava que as firmas japonesas conseguissem se tornar competitivas dentro de um período de sete anos. De fato, a empresa Nissan conseguiu assimilar com sucesso a tecnologia estrangeira e iniciar a produção de componentes no Japão dentro desses sete anos. Outras montadoras japonesas demoraram anos adicionais para conseguirem desenhar e produzir seus próprios componentes automotivos, mas vieram a se tornar empresas de renome internacional. Essa política foi fundamental para promover a aquisição de conhecimento e tecnologia estrangeira pelas montadoras japonesas, bem como para induzir a competição entre firmas na indústria automotiva doméstica (Cusumano, 1985, p. 7-8). Cusumano $(1985$, p. 7) resume a importância das políticas governamentais nos anos iniciais da indústria automotiva no Japão da seguinte forma:

As políticas protecionistas de sucessivos governos japoneses possibilitaram que empresas domésticas fizessem seus testes e experimentações na indústria automobilística e sobrevivessem, apesar da existência de competidores maiores e mais eficientes nos Estados Unidos e na Europa, que estavam ansiosos para exportar para o Japão (Cusumano, 1985, p. 7, tradução nossa). 
É interessante observar que a qualidade dos veículos produzidos pela Toyota e pela Nissan nos anos iniciais da indústria automotiva no Japão era insatisfatória e os militares constantemente reclamavam da sua durabilidade e confiabilidade (Fujimoto, 1999, p. 35). Não obstante, havia um claro incentivo por parte do governo no sentido de fortalecer as empresas domésticas em vez de trazer montadoras estrangeiras para produzir no país. É também importante mencionar que o Japão possui várias montadoras que se originaram em outros setores industriais, tais como aeronáutico e de maquinário têxtil. Os predecessores da Mitsubishi Motors, Fuji Heavy Industries e Prince Motors, por exemplo, todos produziam aeronaves durante a guerra e somente entraram no ramo automotivo em 1945. Toyo Kogyo (renomeada como Mazda em 1984) e Daihatsu foram previamente do ramo de máquinas de precisão e se tornaram montadoras na década de 1950 (Cusumano, 1985, p. 14-15). A Toyota, originariamente Toyoda Automatic Loom, era uma firma do ramo de maquinário têxtil. A determinação do MITI em criar uma indústria automotiva no país durante a década de 1950 foi essencial para facilitar o acesso ao crédito em bancos por parte dessas empresas e fomentar o desenvolvimento desse setor industrial no Japão (Cusumano, 1985, p. 20).

$\mathrm{Na}$ indústria automotiva, o governo japonês adotou uma política de incentivo à exportação no intuito de aumentar a demanda para carros japoneses e estimular as montadoras nacionais a adequarem a qualidade dos veículos produzidos no país aos padrões internacionais. A figura a seguir demonstra a expansão significativa das exportações do Japão no período pós-guerra na indústria automotiva.

Percentual de exportação sobre a produção total japonesa no setor automotivo (1957-1984)

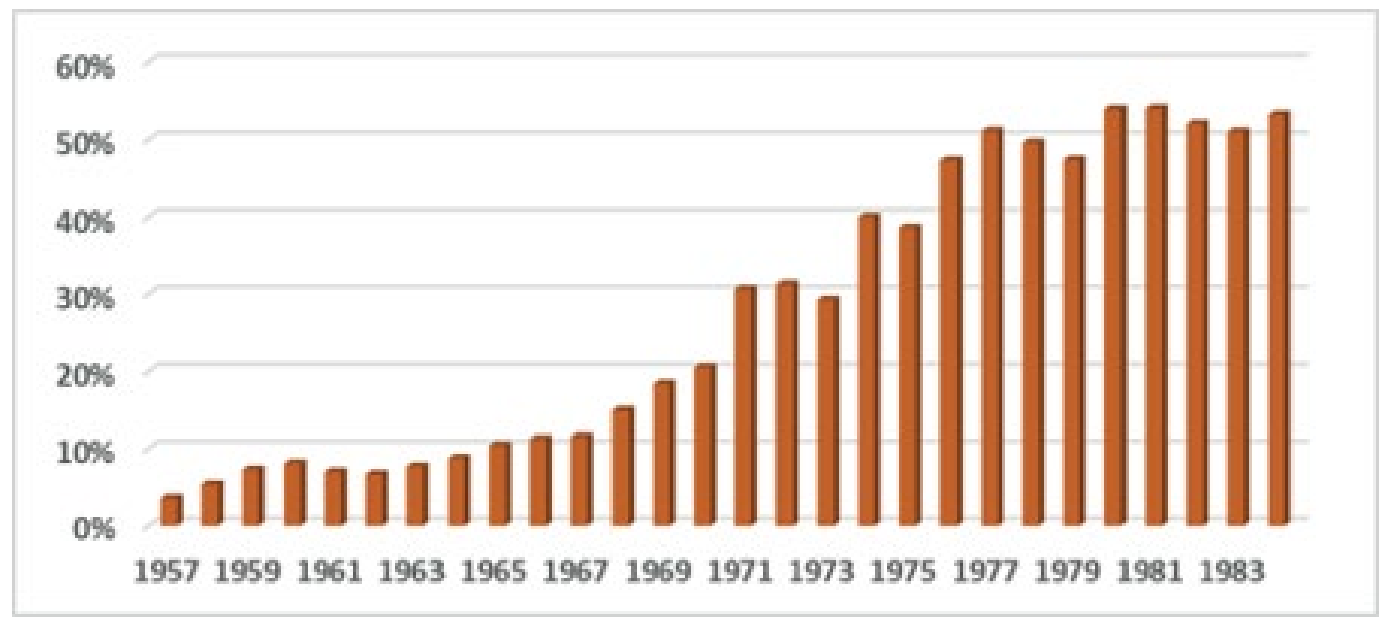

Fonte: Cusumano, 1958, p. 394-395. 
Em outros setores industriais, o governo japonês adotou medidas diferentes para ampliar a demanda de produtos japoneses. No caso de indústrias de alto conteúdo tecnológico, por exemplo, o poder de compra do governo foi amplamente utilizado com tal finalidade. Empresas públicas como a NTT Communications adotaram medidas de priorização de produtos japoneses em seus processos licitatórios, ampliando a demanda de bens e serviços de empresas locais (Patrick, 1986, p. 24-25).

Assim, foram inúmeras as formas pelas quais o governo japonês fomentou 0 crescimento das empresas japonesas em indústrias estratégicas no período pós-guerra. É importante ressaltar, entretanto, que o padrão contínuo de troca de informações, negociação e parceria visando ao alcance de objetivos mútuos entre o governo e a iniciativa privada manteve-se como uma constante em diversos setores industriais.

Em complemento a atuação governamental, merece destaque também a atuação das empresas japonesas na geração do que Ocampo (2017, p. 79) denomina complementaridades. Tais complementaridades encontram-se associadas ao desenvolvimento de redes (networks) de fornecedores, organizações e instituições, capazes de disseminar informações e promover a coordenação entre agentes. As complementaridades possuem papel importante para reduzir o custo da troca de informações, tanto em relação ao mercado quanto à tecnologia, e para difundir inovações e promover efeitos de encadeamento (linkages), seja dentro de um mesmo setor industrial, seja entre diferentes indústrias. Essas complementaridades mostram-se fundamentais para promover uma transformação dinâmica das estruturas produtivas, o que, para Ocampo (2017, p. 94), constitui elemento fundamental para proporcionar o crescimento rápido de países em desenvolvimento.

No caso do Japão, observa-se que as empresas do setor automotivo tradicionalmente fomentam intensas trocas de informações, estimulam a transferência de tecnologia e realizam processos conjuntos de solução de problemas não apenas entre a montadora e os fornecedores, como também em nível horizontal entre fornecedores. Dyer e Nobeoka (2000, p. 352) destacam o papel da associação de fornecedores da Toyota na promoção de um processo contínuo e colaborativo de intercâmbio de informação e tecnologia entre empresas pertencentes à cadeia de suprimentos dessa montadora japonesa.

Como um comentário final, cumpre destacar que parte da literatura critica a intervenção do Estado na economia e defende um menor escopo de ação governamental em políticas industriais, sob a alegação de que o governo é ineficiente em lidar com as falhas de mercado e que maiores níveis de crescimento econômico podem ser alcançados por intermédio da promoção do livre mercado e da autorregulação pela própria iniciativa privada (Shapiro, 2007, p. 2-3; Orbach, 2013, p. 44- 
46). De fato, alguns estudos estatísticos procuram demonstrar que o programa de empréstimo e investimento fiscal japonês teve reduzida ou nenhuma influência nos altos índices de crescimento industrial observados no pós-guerra, e assim suscitam dúvidas sobre a relevância da intervenção estatal no desenvolvimento econômico do país (Noland \& Pack, 2005; Esteban-pretel \& Sawada, 2014).

Não obstante, conforme assinala Esteban-pretel e Sawada (2014, p. 78), diversos pesquisadores ressaltam que uma das vantagens centrais do modelo de intervenção do Estado no Japão estava exatamente na troca constante de informações, no diálogo, na persuasão e na indicação de rumos a serem seguidos pelas empresas, uma vez que os créditos diretamente aportados pelo governo não atingiram $10 \%$ do total de empréstimos contraídos pelo setor industrial. Além disso, conforme discutido acima, o governo japonês não utilizou apenas subsídios financeiros e fiscais em suas políticas, mas também interviu de outras maneiras para estimular empresas em setores industriais estratégicos. Conforme assevera Johnson (1983, p. 203), as empresas japonesas no período pós-guerra dependiam dos bancos comerciais para obter cerca de $70 \%$ a $80 \%$ do seu capital, mas era o banco central japonês, ou Banco do Japão (Nippon Ginkō 日本銀行), o responsável por fornecer esses créditos em última análise.

Dessa forma, o presente artigo argumenta que, em vez de se questionar, de forma teórica, a relevância da intervenção governamental em si, parece mais apropriado explorar qual o padrão intervencionista adequado para o estágio real de desenvolvimento industrial em que se enquadra determinada nação, bem como analisar até que ponto o governo deve exercer influência sobre o mercado em um ambiente macroeconômico específico.

\section{RAZÕES EXÓGENAS PARA O SUCESSO DO MODELO DO ESTADO DE- SENVOLVIMENTISTA E A POSSIBILIDADE DE SUA APLICAÇÃO NO MUNDO GLOBALIZADO CONTEMPORÂNEO}

Apesar do êxito obtido no período pós-guerra pelo Japão, Coreia do Sul e Taiwan, diversos autores enfatizam que países em desenvolvimento atualmente podem não conseguir reproduzir os altos índices de crescimento econômico das nações do leste asiático ao emularem os principais componentes do modelo do Estado desenvolvimentista, em função de uma série de fatores históricos específicos e diferenças substanciais na economia mundial contemporânea (Pempel, 1999a). Conforme discutido na seção anterior, o Estado desenvolvimentista utilizou-se de barreiras tarifárias e outros tipos de políticas protecionistas para restringir a demanda por produtos importados e promover o desenvolvimento de indústrias locais. Tais 
medidas protecionistas, entretanto, foram aliadas a programas de fomento à exportação e usadas como parte de uma política de longo prazo centrada em estimular firmas nacionais a adquirirem experiência e atingirem economia de escala.

Como resultado, produtores locais obtiveram assistência técnica inestimável de compradores e fornecedores estrangeiros e aumentaram progressivamente os seus padrões de qualidade (Wade, 1990, p. 359-363). Além disso, as políticas de estímulo à exportação dos países do leste asiático foram extremamente beneficiadas pelo auxílio norte-americano. Os Estados Unidos abriram os seus mercados ao Japão, à Taiwan e à Coreia do Sul, além de oferecerem assistência de alta qualidade porque, ao diferenciar esses três países das nações socialistas vizinhas, poderiam demonstrar a superioridade do liberalismo e da economia de mercado. Esses três países também receberam apoio norte-americano por questões de segurança, pois sua posição geográfica era mais estratégica para o perímetro de defesa dos Estados Unidos do que outras nações como Filipinas, Indonésia ou Brasil (Wade, 1990, p. 346). Esse apoio norte-americano incluía assistência técnico-financeira, além de um mercado sempre receptivo às exportações dos três países.

Além disso, as nações do leste asiático receberam apoio de outros países para implementar suas reformas agrárias. Na verdade, a reforma agrária é de difícil consecução sem intervenção de um agente externo, pois envolve a destituição do poder de elites locais. No Japão, a reforma agrária foi realizada pelos Estados Unidos, logo após o término da Segunda Guerra Mundial. Na Coreia do Sul, ela foi iniciada pelo governo colonial japonês e concluída pelas forças norte-americanas de ocupação, depois da Guerra da Coreia. Em Taiwan, a reforma agrária também foi iniciada pelo governo japonês no período colonial, e finalizada pelo Kuomintang, o Partido Nacionalista Chinês. Em todos esses países, a reforma agrária facilitou a industrialização, removendo os privilégios das elites locais e centralizando o poder nas mãos do Estado. Ademais, ela também redirecionou o capital ocioso, que antes se encontrava na especulação fundiária, para atividades manufatureiras (Amsden, 1989, p. 37; Wade, 1990, p. 301-302; Pempel, 1999b). Finalmente, a realização de reformas agrárias resultou em uma melhor distribuição de renda nessas economias, o que também contribuiu para a industrialização, uma vez que induziu alto fluxo de recursos, antes alocados na distribuição de produtos primários, para a manufatura (Amsden, 2001, p. 18).

Além de tais peculiaridades de cunho histórico, outra barreira à adoção do modelo do Estado desenvolvimentista no mundo de hoje é o fato de que os governos atuais possuem menor controle sobre suas firmas e seus mercados internos. 
Em primeiro lugar, na atualidade os Estados apresentam menor capacidade de administrar o rápido fluxo de entrada e saída de capital privado em suas economias domésticas. Por exemplo, Pempel (1999b) assevera que os países asiáticos que foram menos afetados pela crise asiática de 1997 foram Taiwan, China e Filipinas, exatamente aqueles que exibiam baixos níveis de capital volátil. Atualmente, os Estados mostram-se apenas parcialmente capazes de controlar o fluxo de recursos financeiros na economia, o que os torna vulneráveis a especuladores internacionais. Em segundo lugar, deve-se ter em mente que as empresas estão operando cada vez mais em nível regional e não apenas doméstico. Como resultado, a divisão do trabalho tende a ocorrer de forma globalizada, envolvendo diferentes regiões geográficas ao mesmo tempo. Aliado a isso, observa-se que muitas delas estão utilizando-se de global sourcing e implementando cadeias de suprimento que transcendem as fronteiras nacionais e englobam simultaneamente vários países. Dessa forma, a estrutura doméstica dos Estados encontra-se progressivamente inserida em mercados regionais ou globais. Portanto, até certo ponto, pode-se dizer que o livre comércio e a globalização do mercado mundial estão enfraquecendo a capacidade dos Estados de exercer controle sobre suas economias domésticas.

Além disso, a eficácia do Estado em direcionar investimentos do setor privado em indústrias de interesse nacional, de acordo com objetivos de políticas industriais, também se encontra ameaçada pelo surgimento de formas alternativas mediante as quais as empresas podem conseguir capital no mercado internacional. O controle do governo sobre o sistema bancário e a necessidade da aprovação estatal para obter acesso a empréstimos são fatores relevantes para explicar o grande comprometimento das empresas com as políticas definidas pelo governo, no âmbito do modelo do Estado desenvolvimentista (Wade, 1990). No Japão, desde o período Meiji, recursos provenientes de instituições financeiras eram predominantes se comparados ao capital industrial e, assim, os bancos desempenharam um papel fundamental no financiamento do desenvolvimento industrial (Norman, 2000, p. 112; Johnson, 1983, p. 203). A burocracia estatal japonesa, portanto, conseguiu exercer tradicionalmente pressão significativa para que suas regras e recomendações fossem obedecidas pelo setor privado por possuir ampla discricionariedade nas suas decisões e alto controle sobre as principais fontes de financiamento.

Essa fonte de pressão por parte do Estado encontra-se atualmente ameaçada em função da capacidade de grandes empresas de obterem recursos financeiros no mercado internacional e pela crescente mobilidade internacional dos empreendimentos. À medida que o Estado desenvolvimentista perde um dos seus principais instrumentos de barganha, fica reduzida a eficácia da burocracia estatal em direcio- 
nar o setor privado de acordo com os interesses nacionais. Um caso emblemático foi o da empresa Toyota, que em 1998 recusou-se a injetar capital no Banco Mitsui, apesar da grande pressão estatal (Dore, 2000). No passado, as empresas apresentavam menor mobilidade internacional e viam o nacionalismo econômico do Estado como benéfico aos seus interesses. Ao contrário, agora que as firmas possuem maior mobilidade, o nacionalismo estatal acaba sendo visto como um obstáculo na procura por melhores oportunidades de lucro na esfera internacional (Wade, 1990).

Há, ainda, uma pressão crescente por parte de instituições internacionais, tais como a Organização Mundial do Comércio, o Banco Mundial e o Fundo Monetário Mundial, para que todas as nações do mundo adotem leis de propriedade intelectual, seguindo o arcabouço legal norte-americano, garantam o livre mercado (Chang, 2011, p. 474-475), restrinjam a utilização de políticas de fomento voltadas à concessão de privilégios para empresas locais etc. (Cunha, 2012, p. 300). Tratados internacionais como o Acordo de Compras Governamentais (GPA) procuram assegurar que os Estados signatários promovam maior igualdade de tratamento entre empresas domésticas e internacionais em seus processos licitatórios, limitando assim o uso do poder público de compras para estimular o crescimento de empresas locais (Sorte Junior, 2018, p. 1000).

Já outras convenções internacionais, como o Acordo sobre Aspectos dos Direitos de Propriedade Intelectual Relacionados ao Comércio (Agreement on Trade-Related Aspects of Intellectual Property Rights ou TRIPS), dificultam a realização de engenharia reversa para promover uma mais ampla utilização de tecnologias desenvolvidas no exterior por países em desenvolvimento (Cunha, 2012, p. 300). Destaca-se que, em muitos casos, como o do Japão e da Coreia do Sul, o processo de imitação tecnológica foi um importante ponto de partida para o processo de emparelhamento (catching up) tecnológico, marcado por esforços para redução da diferença de desenvolvimento entre esses países e as nações mais poderosas da época (Pereira \& Dathein, 2015, p. 280). Esse maior rigor das instituições internacionais também constitui um empecilho aos Estados no mundo contemporâneo na implementação de incentivos e subsídios em suas políticas industriais.

A maior legitimidade da burocracia estatal nos países do leste asiático em comparação com outras nações é outro ponto que merece ser levado em consideração por governos interessados em adotar o modelo do Estado desenvolvimentista. Woo-cumings (1999) afirma que o Estado intervencionista na Coreia do Sul tem se mostrado extremamente centrado em resultados, privilegiando o alcance de objetivos em vez do simples cumprimento de regras e assevera que decre- 
tos administrativos e não leis constituem os instrumentos normativos dominantes. Schapiro (2018, p. 579) assinala que o modelo desenvolvimentista é marcado por alto nível de discricionariedade da administração pública, uma vez que há "uma alocação abrangente de poder decisório para a burocracia do Executivo, de forma a habilitar uma atuação sujeita a menor constrangimentos legais sobre os limites da competência delegada".

Conforme destacado na seção anterior, no Japão a burocracia estatal caracteriza-se pelo vasto uso de recomendações governamentais, isto é, sugestões de caráter informal que são, na maioria das vezes, rigorosamente seguidas pelo setor privado. Nesse sentido, Haley (1991) sustenta que as autoridades públicas japonesas detêm muito poder real de intervenção mesmo quando não possuem os meios legais de coerção necessários. Por isso, a lei tradicionalmente tem apresentado um papel secundário em comparação com as recomendações governamentais no Japão.

Contudo, é interessante ressaltar que essas diretrizes, orientações e direcionamentos de cunho informal parecem ter resultado em uma maior adesão das empresas privadas às políticas industriais do que a abordagem utilizada por governos de países mais centrados na valorização de instrumentos legais de coerção, como é o caso do Brasil. O governo brasileiro tende a atribuir importância ímpar à criação de novas leis e outros instrumentos normativos como tentativa de operacionalizar mudanças no setor privado e no mercado, embora nem sempre consiga atingir os objetivos almejados com a promulgação de tais marcos legais. Em suma, pode-se argumentar que os países do leste asiático atribuem significativa ênfase a um padrão de negociação contínua de modo a alcançar o consenso, em vez de concentrarem-se na promulgação de novas leis visando a ampliação, a regulação e o controle, o que tende a resultar em um nível de intervenção mais efetivo do Estado na economia, consubstanciado em políticas públicas adequadas à promoção do dinamismo industrial e crescimento econômico. Assim, diferenças de ordem sociocultural e política entre nações não podem ser ignoradas na análise de variações nos níveis de sucesso na implementação do modelo do Estado desenvolvimentista.

\subsection{Aplicação do modelo do Estado desenvolvimentista por nações em desenvolvimento no mundo globalizado contemporâneo}

Apesar de existirem diferenças de caráter histórico e relacionadas aos novos desafios de um mercado globalizado, este estudo defende que os países em desenvolvimento ainda podem aprender com a experiência das nações do leste 
asiático no período pós-guerra. Em especial, o relacionamento próximo entre o governo e o setor privado tende a se mostrar como um elemento fundamental no processo de elaboração e implementação de políticas industriais. Na verdade, tanto as autoridades públicas quanto os diretores do setor privado possuem limitações quanto à capacidade de compreender todas as variáveis macroeconômicas e avanços tecnológicos, assim como de interpretar a interação entre as entidades domésticas e internacionais em atuação na economia mundial (Simon, 1965).

Assim, é fundamental não só que as políticas públicas sejam elaboradas em conjunto com o setor privado, de modo a obter insumos mais próximos à realidade do mercado, mas também que seja mantido um canal aberto de interface com as empresas durante a implementação de tais políticas, a fim de que eventuais falhas sejam corrigidas no decorrer do processo, visando ao alcance do objetivo final em longo prazo. Nesse contexto, as principais premissas do modelo do Estado desenvolvimentista ainda parecem aplicáveis. A criação de um relacionamento baseado na colaboração entre o governo e o setor privado é capaz de prover informações essenciais para a elaboração de políticas que atendam de forma adequada às necessidades das empresas domésticas. Pode também fornecer ao governo conhecimento técnico atualizado sobre o avanço tecnológico, permitindo às autoridades públicas um melhor entendimento dos cenários prováveis das mudanças tecnológicas de modo a identificar setores industriais com maior probabilidade de desempenhar um papel relevante no futuro.

A análise da experiência japonesa revela que o processo de transformar empresas domésticas em multinacionais altamente competitivas não resulta apenas de decisões governamentais acertadas acerca de quais setores industriais se deve fomentar, mas também de opções a respeito de quais medidas - incentivos fiscais, subsídios etc. -, quais abordagens - substituição de importações, políticas de apoio à exportação etc. - e quais arranjos institucionais - parcerias público-privadas, comitês interministeriais, agências regulatórias etc. - devem ser utilizados para melhor atender às demandas do setor privado.

Dessa forma, políticas industriais eficazes pressupõem não apenas um processo coerente de planejamento estratégico, mas também mecanismos adequados de monitoração e troca de informação entre o governo e o setor privado que permitam repensar as políticas e adaptá-las a mudanças imprevistas no ambiente político-econômico.

Ao se falar das vantagens do relacionamento próximo entre a burocracia estatal e o setor privado observado no Japão, é necessário destacar que, no caso de determinados países em desenvolvimento como o Brasil, os efeitos nocivos da 
corrupção não podem ser ignorados em se tratando de subsídios públicos ao setor privado. Casos de corrupção resultam em diversos problemas críticos, tais como: atrasos, baixa qualidade e superfaturamento de obras públicas, desvio de verbas em políticas de fomento e alocação indevida de subsídios baseada em interesses pessoais ou favores políticos em vez de objetivos de políticas industriais. Observa-se muitas vezes o conluio entre empresas privadas e servidores governamentais na concessão de financiamentos por bancos públicos de fomento, causando incerteza quanto à aplicação adequada de subsídios estatais para estimular empresas brasileiras em políticas industriais (The Economist, 2011; Fabrini \& Matais, 2016). À proporção que a corrupção se torna endêmica no meio político, cresce a propensão do setor privado de se dedicar mais ao rent seeking do que ao comprometimento com atividades industriais de agregação de valor.

Com relação a esse tópico, vale ressaltar que Schneider $(1999,291)$ identifica o "capitalismo político", caracterizado pela indicação de grande proporção dos servidores públicos com base no nepotismo e clientelismo, como o principal obstáculo ao sucesso do modelo do Estado desenvolvimentista no Brasil e no México. Para ele, essa "burocracia por nomeação" (em inglês, appointive bureaucracy) resulta em baixa autoestima dos servidores públicos, além de vários problemas como excesso de centralização, fragmentação, baixa ética profissional, alta rotatividade, corrupção e treinamento de baixa qualidade. Conforme o autor, essa constitui uma das diferenças marcantes entre o tipo de administração pública existente em países do leste asiático e o predominante em certos países da América Latina, tais como Brasil e México, que seria capaz de explicar em parte a discrepância no nível de eficácia das políticas industriais neles implementadas.

De fato, o poder e a influência excessivos, dos partidos políticos sobre a administração pública brasileira, que se consubstancia no grande número de profissionais nomeados por afiliação partidária ou interesses pessoais exercendo cargos de gestão e comando no poder executivo, podem ser considerados como um empecilho à criação e implementação de políticas industriais eficazes, uma vez que questões políticas acabam se envolvendo até mesmo em matérias de caráter eminentemente técnico. Na verdade, o Estado desenvolvimentista possui como uma de suas características marcantes a existência de um "processo decisório sobre a política econômica amplamente dominado por burocratas econômicos razoavelmente autônomos, em vez de controlada por políticos eleitos" (Perissinotto, 2014, p. 62).

Não obstante, insucessos de políticas industriais resultantes da ação nociva de autoridades governamentais envolvidas em esquemas de corrupção não devem ser vistos como justificativas para reduzir a ação do Estado na economia. É importante 
que se implementem mudanças visando à moralização da política, à redução do desvio de recursos públicos e à coibição de demais atividades ilícitas envolvendo o erário.

Nesse contexto, existem diversos estudos dedicados à análise das diferenças entre o padrão de intervenção do Estado na economia no leste asiático e na América Latina capazes de explicar a diferença do nível de desenvolvimento observado nas duas regiões (Pereira \& Dathein, 2016, p. 42). Enquanto a América Latina (representada por Argentina, Bolívia, Brasil, Chile, Colômbia, México, Peru, Uruguai e Venezuela), reduziu sua participação no produto interno bruto (PIB) mundial de 10,3\% em 1980 para 8,5\% em 2009, os países em desenvolvimento da Ásia (Coreia do Sul, Taiwan, Cingapura, Hong Kong, Malásia, Indonésia, Filipinas, Tailândia, China e Índia) aliados ao Japão intensificaram a sua parcela de 8,9\% em 1980 para 26,2\% em 2009 (Cunha, 2012, p. 295, 311). Dentre algumas das razões apontadas na literatura acadêmica para essa discrepância em crescimento econômico, aponta-se a dificuldade dos países latino-americanos em criar um ambiente institucional favorável para a produção de bens com maior conteúdo tecnológico, focados na exportação para as economias centrais da época (Pereira \& Dathein, 2016, p. 40).

Ao centrar a produção local de suas indústrias em mercados externos altamente competitivos e que demandavam altos padrões tecnológicos e de qualidade, os países do leste asiático forçaram suas empresas a progressivamente aumentarem sua produtividade e seu conteúdo tecnológico, promovendo dinamismo em suas estruturas produtivas. Já no caso da América Latina, mais especificamente do Brasil, o enfoque foi a proteção do mercado interno e atração de multinacionais, o que intensificou a dependência tecnológica nacional e resultou em ineficiência produtiva, "em função da falta de exposição da produção nacional ao mercado internacional" (Pereira \& Dathein, 2016, p. 43). No caso da indústria automotiva brasileira, por exemplo, o governo brasileiro foi bem-sucedido em convencer montadoras internacionais a começarem a produzir veículos no país a partir de 1950 (Sorte Junior, 2011, p. 168). Entretanto, não houve um esforço no sentido de fomentar as montadoras nacionais que tentaram se desenvolver no Brasil, e o setor se tornou dependente da tecnologia estrangeira, bem como de recursos públicos e financiamento externo. Além disso, o uso da política de substituição de importações, sem um foco no estímulo às exportações, resultou em um modelo produtivo que, no máximo, reproduzia as tecnologias vigentes no período, não havendo processos ativos de inovação e efetivo aprendizado tecnológico local (Pereira \& Dathein, 2016, p. 45-46). 
Palma (2010, p. 42) acrescenta a falta de estímulo para agregação de valor nos setores manufatureiros de diversos países da América Latina. No caso da produção de cobre no Chile, por exemplo, o autor assinala que o país vem reduzindo a agregação de valor ao cobre destinado ao mercado externo nos últimos anos, exportando um produto de qualidade mais primitiva. Assim, seria fundamental para promover um maior dinamismo produtivo na América Latina que se procurasse agregar valor ao produto exportado, de forma a tornar possível uma ascensão desses países para posições maiores e mais complexas dentro da cadeia produtiva mundial (Sorte Junior, 2011, p. 171). Conforme assinala Andreoni e Chang (2019, p. 141), atualmente os países em desenvolvimento, em especial na África e América Latina, muitas vezes são induzidos a crer que precisam integrar seus setores industriais internos a uma cadeia global de suprimentos, o que os leva a negligenciar o desenvolvimento de seus sistemas locais de produção e o processo de agregação de valor no âmbito da indústria doméstica.

Excluindo-se a análise de políticas macroeconômicas, que não constitui o escopo do presente estudo, e limitando-se esta discussão à área de políticas industriais, entende-se que o papel do estado é fundamental para estimular maior dinamismo industrial e atualização tecnológica. A ideia de se fomentar certos setores industriais com grande potencialidade de gerar externalidades, de modo a torná-los internacionalmente competitivos, foi amplamente utilizada por países do leste asiático, com resultados positivos. A experiência japonesa apresentada na seção anterior revela o papel preponderante de decisões governamentais adequadas durante o processo de planejamento e implementação de políticas industriais para a transformação de empresas domésticas em multinacionais de destaque internacional.

Dessa forma, este artigo sustenta que, no que tange a políticas industriais, as premissas básicas do modelo do Estado desenvolvimentista ainda se mostram relevantes para a realidade econômica mundial, e diversos países emergentes podem se valer da experiência de sucesso dos países do leste asiático no período pós-guerra. Em especial, a seleção e o fomento de setores industriais estratégicos e a criação de um relacionamento próximo entre o governo e o setor empresarial, de modo a maximizar o alcance de objetivos mútuos, continuam premissas válidas para a realidade econômica atual e para o nível de desenvolvimento industrial de países em desenvolvimento.

$\mathrm{Na}$ verdade, observa-se que muitas vezes a ineficiência de determinadas políticas públicas acaba se tornando justificativa para o fortalecimento de teorias que se opõem à intervenção estatal. É importante destacar, entretanto, que até mesmo gestores públicos experientes e desprovidos de interesses escusos po- 
dem vir a tomar decisões imprecisas, resultando em políticas inadequadas para determinada realidade econômica. É possível também que políticas públicas bem definidas apresentem falhas no momento de sua implementação, tornando-se ineficazes. Entretanto, isso constitui um resultado possível de qualquer processo decisório, seja no âmbito de políticas públicas ou no planejamento estratégico de uma empresa privada. Ao discutir o conceito de falha do Estado (em inglês, government failure), por exemplo, Orbach (2013, p. 51) assevera que, enquanto no Direito Societário as normas que regem as obrigações fiduciárias e as decisões empresariais enfatizam que diretores e gerentes podem cometer erros, é comum, tanto aos críticos quanto aos adeptos da regulação da economia pelo Estado, enquadrarem desvios de políticas públicas das normas ideais e soluções teóricas como falhas de governo. Assim, a dificuldade de se planejar e implementar políticas industriais não deve ser encarada como justificativa para uma menor intervenção do Estado na economia, e sim como uma evidência da importância de se criar um relacionamento próximo entre setores público e privado, em sintonia aos princípios básicos do modelo do Estado desenvolvimentista, de modo a permitir a correção e readequação de eventuais falhas no processo de implementação de políticas industriais.

\section{CONCLUSÃO}

O presente trabalho apresentou o modelo de intervenção estatal na economia utilizado pelo Japão e outros países do leste asiático, conhecido como modelo do Estado desenvolvimentista, a fim de identificar os principais elementos responsáveis pelo alcance de altos índices de crescimento industrial e econômico alcançados por essas nações no período pós-guerra. Tal modelo é caracterizado pelo esforço exaustivo de identificar setores industriais capazes de desempenhar um papel central na promoção do crescimento industrial em longo prazo e de fomentar empresas domésticas nesses setores. O relacionamento entre governo e setor privado é baseado na troca constante de informações e na colaboração, de modo a permitir a consecução de objetivos mútuos. A política industrial japonesa no período pós-guerra, portanto, envolveu não apenas um processo eficiente de planejamento estratégico, mas também um padrão constante de monitoração e acompanhamento, a fim de readaptar os objetivos e as medidas previamente estipuladas de acordo com as mudanças de mercado e necessidades das empresas locais.

O tema objeto de análise neste artigo mostra-se atual em função do surgimento de abordagens alternativas que defendem a adoção de novos modelos do 
desenvolvimentismo, nos quais o papel central do Estado estaria no controle de preços macroeconômicos, em especial a taxa de câmbio e a taxa de juros. Sob esses novos paradigmas, o governo desenvolvimentista não mais concentraria o seu enfoque na política industrial, mas sim na política macroeconômica nacional. Apesar de reconhecerem a relevância da política industrial, essas novas abordagens a consideram como subsidiária, sendo que a função primordial do Estado residiria agora na criação de um ambiente macroeconômico favorável (Pereira \& Dathein, 2016, p. 48-49). De fato, pode-se argumentar que políticas macroeconômicas brasileiras recentes centradas na promoção de taxas de câmbio sobrevalorizadas minaram diversos setores industriais orientados à exportação (Andreoni \& Chang, 2019 , p. 136), o que tende a demonstrar que o resultado de políticas industriais encontra-se intrinsecamente relacionado às variáveis macroeconômicas.

Não obstante, entende-se que políticas industriais constituem o cerne do modelo do Estado desenvolvimentista e, apesar das mudanças do mundo atual, ainda constituem um instrumento fundamental para os países em desenvolvimento, que enfrentam dificuldades em aperfeiçoar suas estruturas produtivas e consolidar seus investimentos em inovação, de modo a atingirem níveis de crescimento similares aos países desenvolvidos e se tornarem competitivos no mercado global. Assim, o que se observa atualmente não é a obsolescência do conceito de política industrial e sim o surgimento de novos desafios impostos pelo ambiente econômico mundial, que impõem a necessidade de um alinhamento das políticas industriais com stakeholders detentores de interesses muitas vezes conflitantes; ambientes político-econômicos cada vez mais dinâmicos; demandas e exigências de instituições nacionais e organismos internacionais; ordenamentos jurídicos mais rigorosos etc. (Andreoni \& Chang, 2019, p. 148). Conforme assevera Aiginger (2014), a política industrial voltou a ter papel central na agenda dos governos, inclusive de países desenvolvidos, principalmente a partir da crise financeira mundial recente, embora atualmente inclua novos desafios, tais como: a necessidade de integração com outras políticas públicas; responder apropriadamente a demandas sociais; considerar questões ambientais; e influenciar a estrutura da economia de forma geral e não somente o setor manufatureiro.

$\mathrm{Na}$ verdade, a atuação do Estado no sentido de promover o dinamismo econômico na forma de políticas industriais justifica-se porque o setor industrial de um país é capaz de:

(...) gerar impactos superiores em termos de encadeamentos das cadeias produtivas (efeito estrutural), pelas economias de escala e escopo (efeito microeconômico), 
pelo ritmo de inovação (efeito tecnológico), no sentido de possuir maiores elasticidades-renda da demanda dos produtos exportados, diminuindo restrições de balanço de pagamentos (efeito macroeconômico), pela maior dispersão territorial possível da produção (efeito regional) e considerando a crescente e ampla relação ou encadeamentos entre indústria e serviços empresariais de alta qualificação (Pereira \& Dathein, 2016, p. 33-34).

Além disso, por intermédio da política industrial, o Estado pode coordenar a criação de instituições que darão suporte ao processo de transformação dinâmica das estruturas produtivas, gerando complementaridades e spillovers não só dentro de setores industriais, como também entre diferentes indústrias.

Como um comentário final, vale destacar uma questão relevante relacionada ao papel dos demais setores produtivos no desenvolvimento econômico dos países no mundo atual. Conforme assinala Szirmai (2012, p. 417), existe evidência histórica de que o setor industrial exerceu papel importante no desenvolvimento econômico de diversos países em desenvolvimento desde 1950, principalmente na Ásia. De fato, a manufatura teve uma função de destaque, principalmente em função da sua capacidade de promover a acumulação de capital, economias de escala e progresso tecnológico (Szirmai, 2012, p. 415). Não obstante, observam-se algumas mudanças em relação a esses elementos nas últimas décadas. Com o advento das tecnologias da informação e comunicação (TIC), por exemplo, constatam-se consideráveis acréscimos em economias de escala no setor de serviços, inclusive casos em que o custo marginal de aquisição de uma unidade adicional de determinado serviço torna-se praticamente zero (Szirmai, 2012: 416). Levitt (1972, p.10-11), em seu estudo sobre a rede McDonald's, também enfatiza a possibilidade de incremento substancial na produtividade no setor de serviços por meio da padronização de atividades e procedimentos, o que para o autor corresponderia a aplicação do conceito da linha de produção da indústria manufatureira ao setor de serviços. Além disso, verifica-se que a agricultura tem se tornado um setor com alto grau de capital intensivo, em função de avanços tecnológicos e nos modos de produção (Szirmai, 2012, p. 415). Dessa forma, é importante considerar se outros setores da economia, principalmente o de serviços, podem vir a assumir a função anteriormente desempenhada pelo setor industrial, como motor do desenvolvimento econômico, o que implicaria na necessidade de rever premissas do modelo do Estado desenvolvimentista.

Nesse contexto, é interessante assinalar que Szirmai (2012, p. 417) afirma ainda não haver experiências de países que foram capazes de atingir níveis substanciais de desenvolvimento econômico com base no setor de serviços ou agrope- 
cuário, de forma similar ao papel desempenhado pela indústria na experiência das nações do leste asiático. De fato, conforme assinala o autor, pelo corolário da Lei de Engel, à medida que a renda per capita de um país aumenta, há uma tendência de declínio da demanda por produtos agrícolas e um incremento na procura por produtos industrializados, de tal sorte que se o país prossegue como uma nação basicamente agrícola, será forçado a importar cada vez mais bens manufaturados, exercendo impacto negativo em sua balança de pagamentos. Também em inúmeras áreas do setor de serviços, como governo, restaurantes, hotéis, atendimento médico, educação, turismo e higiene pessoal opera-se a Lei de Baumol, segundo a qual um aumento da quantidade de serviços disponíveis resulta em uma desaceleração da produtividade (Szirmai, 2012, p. 416-417). Baumol (1967, p. 416) também enfatiza que no setor de serviços o trabalho humano normalmente constitui uma parte indispensável do bem final comercializado, como é o caso da atuação de um professor, enquanto que na indústria a função do trabalho é instrumental e pode ser substituída por máquinas, o que facilita o aumento da produtividade nesse setor em comparação com aquele. Além disso, observa-se que os linkages, spillover effects e a pressão por avanços tecnológicos ainda tendem a ser maiores no setor manufatureiro. Pode-se concluir, portanto, que embora o setor de serviços responda por uma parcela cada vez maior do PIB dos países tanto em desenvolvimento quanto desenvolvidos e que em muitas áreas desse setor a referida Lei de Baumol já não tem aplicação plena em função de avanços em TIC e da crescente padronização de atividades, a indústria ainda terá um papel central como propulsor do desenvolvimento econômico no mundo atual.

\section{REFERÊNCIAS}

Aiginger, K. (2014). Industrial Policy for a sustainable growth path. Policy Paper n. 13, WWWforEurope, Austrian Institute of Economic Research (WIFO). Recuperado de http://www.oecd.org/economy/Industrial-Policy-for-a-sustainable-growth-path.pdf.

Amsden, A. H. (1989). Asia's Next Giant: South Korea and Late Industrialization. Oxford: Oxford University Press.

Amsden, A. H. (2001). The Rise of "the Rest": challenges to the West from Late-industrializing Economies. Oxford: Oxford University Press.

Andreoni, A. \& Chang. H-J. (2019). The political economy of industrial policy: Structural interdependencies, policy alignment and conflict management. Structural Change and Economic Dynamics, v. 48, p. 136-150. 
Baumol, W. J. (1967) Macroeconomics of Unbalanced Growth: The Anatomy of urban Crisis. The American Economic Review, v. 57(3), p. 415-426).

Beltramini, E. (2014). Carta do Editor. Revista Síntese Direito Empresarial, nº 38 , p. 3.

Bresser-Pereira, L. C. (2018). Nacionalismo econômico e desenvolvimentismo. Economia e Sociedade, v. 27(3), p. 853-874.

Chang, H-J. (2011) Institutions and economic development: theory, policy and history. Journal of Institutional Economics, v. 7(4), p. 473-498.

Cunha, A. M. (2012). O paradigma do estado desenvolvimentista e o "retorno" da política industrial. Pesquisa \& Debate, v. 23(2), p. 291-316.

Dore, R. (2000). Stock Market Capitalism: Welfare Capitalism - Japan and Germany versus the Anglo-Saxons. Nova York: Oxford University Press.

Dyer, J. H. \& Nobeoka, K. (2000). Creating and Managing a High-performance Knowledge-sharing Network - The Toyota Case. Strategic Management Journal, v. 21(edição especial), p. 245-367.

Esteban-pretel, J. \& Sawada, Y. (2014). On the role of policy interventions in structural change and economic development: The case of postwar Japan. Journal of Economic Dynamics \& Control, v. 40, p. 67-83.

Evans, P. (1995). Embedded Autonomy: States and Industrial Transformation. Princeton: Princeton University Press.

Fabrini, F.; Matais, A. (2016). PF indicia Pimentel e Marcelo Odebrecht por corrupção no BNDES. O Estadão, 15 set. 2016. Recuperado de http://politica.estadao.com.br/blogs/coluna-do-estadao/ pf-indicia-pimentel-e-marcelo-odebrecht-por-corrupcao-no-bndes/.

Fujimoto, T. (1999). The Evolution of a Manufacturing System at Toyota. Nova York: Oxford University Press.

Haley, J. O. (1991). Authority without Power: Law and the Japanese Paradox. Nova York: Oxford University Press.

Johnson, C. A. (1983). MITI and the Japanese miracle: the growth of industrial policy, 1925-1975. Stanford: Stanford University Press.

Levitt, T. (1972). Production-line approach to service. Harvard Business Review, reprint 72505.

Kohli, A. (1999). Where do high-growth political economies come from? The Japanese lineage of Korea's "Developmental State". In: Woo-cumings, M. (org.). The developmental State. Nova York: Cornell University Press, p. 93-136. 
Mandlate, O. E. C. (2013). Ligações a montante dos grandes projectos de IDE e diversificação da economia: estudo de caso de quatro empresas ligadas com a Mozal. (Tese de mestrado). Maputo: Instituto Superior de Ciências e Tecnologia de Moçambique.

Mankiw, N. G. (2008). Principles of Microeconomics. (5 $5^{\mathrm{a}}$ ed). Mason, South-Western Cengage Learning.

Matias-pereira, J. (2010). Governança no Setor Público. São Paulo: Atlas.

Noland, M. \& Pack, H. (2005). The East Asian Industrial Policy Experience: Implications for the Middle East, Working Paper 05-14. Recuperado de https:// piie.com/sites/default/files/publications/wp/wp05-14.pdf.

Norman, H. E. (2000). Japan's Emergence as a Modern State: Political and Economic Problems of the Meiji Period. (edição do $60^{\circ}$ aniversário). Vancouver: University of British Columbia Press.

Ocampo, J. A. (2017). Dynamic Efficiency: Structural Dynamics and Economic Growth in Developing Countries. In: Norman, A. \& Stiglitz, J. E. (org.). Efficiency, Finance, and Varieties of industrial Policy: Guiding Resources, Learning and Technology for Sustained Growth. Nova York: Columbia University Press, p. 65-102.

Orbach, B. (2013). What Is Government Failure. Yale Journal on Regulation Online, v. 30(44), p. 44-56.

Palma, J. G. (2010). Why Has Productivity Growth Stagnated in Most Latin American Countries since the Neo-Liberal Reforms? The Economic Consequences of a Rentier-Dominated Power Structure and a Narcissistic Ideology. Cambridge University, Cambridge Working Papers in Economics 1030. Recuperado de http://www.econ.cam.ac.uk/research-files/repec/cam/pdf/cwpe1030.pdf.

Patrick, H. (1986) Japanese high technology industrial policy in comparative context. Working Paper n. 1. Recuperado de https://core.ac.uk/download/ pdf/161435992.pdf.

Pempel, T. J. (1999a) Conclusion. In: Pempel, T. J. (ed.) The politics of the Asian economic crisis. Nova York: Cornell University Press, p. 224-238.

Pempel, T. J. (1999b). The Developmental Regime in a Changing World Economy. In: Woo-cumings, M. (ed.). The developmental State. New York: Cornell University Press, p. 137-181.

Pereira, A. J. \& Dathein, R. (2015). Processo de aprendizado, acumulação de conhecimento e sistemas de inovação: a "coevolução das tecnologias físicas e sociais" como fonte de desenvolvimento econômico. In: Dathein, R. (org.) 
Desenvolvimentismo: o conceito, as bases teóricas e as políticas. Porto Alegre: Editora da UFRGS.

Pereira, A. J. \& Dathein, R. (2016). Política industrial como instituição desenvolvimentista: uma crítica ao "novo desenvolvimentismo" baseada nas experiências de brasil e coreia do sul. Revista de Economia Contemporânea, 20(1), p. 28-57.

Perissinotto, R. (2014). O conceito de estado desenvolvimentista e sua utilidade para os casos brasileiro e argentino. Revista de Sociologia Política, v. 22(52), p. 59-75.

Schapiro, M. G. (2018). Do estado desenvolvimentista ao estado regulador? transformação, resiliência e coexistência entre dois modos de intervenção. Revista Estudos Institucionais, v. 4(2), p. 572-614.

Schneider, B. R. (1999) The Desarrollista State in Brazil and Mexico. In: Woo-Cumings, M. (org.), The Developmental State. Ithaca: Cornell University Press, p. 276-305.

Simon, H. A. (1965) Administrative Behavior: A study of Decision-Making Processes in Administrative Organization. Nova York: The Free Press.

Shapiro, H. (2007). Industrial Policy and Growth. DESA Working Paper No. 53, 2007. Recuperado de http://www.un.org/esa/desa/papers/2007/wp53_2007. pdf.

Sorte Junior, W. F. (2011). Assessing Brazilian Government Efficiency in Nurturing the Private Sector: A Cross-Sectoral Analysis on Industrial Policy. In: Kimura, H; Megasejati, N. P. \& Javier, A. B. (eds.). Limits of Good Governance in Developing Countries. Yogyakarta: Gadjah Mada University Press, p. 138-181.

Sorte Junior, W. F. (2014). Does the Japanese inclination towards non-litigation hinder access to justice for minority groups?. International Journal of Public Law and Policy. v. 4(3), p. 221-244.

Sorte Junior, W. F. (2018). O uso do poder público de compra em políticas industriais: uma comparação entre Brasil e Japão. Revista de Administração Pública, v. 52, n. 5, p. 997-1006.

Sperotto, F. Q. (2003). Externalidades, ganhos de escala e escopo. In: Conceição, C. S. \& Feix, R. D. (eds) Elementos conceituais e referências teóricas para o estudo de Aglomerações Produtivas Locais. Porto Alegre: Secretaria do Planejamento, Gestão e Participação Cidadã, Governo do Estado do Rio Grande do Sul, p. 23-31.

Szirmai, A. (2012). Industrialisation as an engine of growth in developing countries, 
O MODELO DO ESTADO DESENVOLVIMENTISTA JAPONES: ASPECTOS HISTÓRICOS E CONSIDERAÇÕES SOBRE SUA RELEVÂNCIA NO MUNDO CONTEMPORÂNEO

1950-2005. Structural Change and Economic Dynamics, v. 23, p. 406-420.

The Economist. (2011). Politics in Brazil - Cleaning the Brasília Pork Factory: In a Never-Ending Telenovela of Sleaze, Dilma Rousseff is Tackling the Excesses of Patronage Politics But Not Yet the Underlying System. The Economist, (edição impressa), 26 nov. 2011.

Thirlwall, A. P. (2011). The balance of payments constraint as an explanation of international growth rate differences. PSL Quarterly Review, v. 64(259), p. 429-438.

Wade, R. (1990) Governing the Market: Economic Theory and the Role of Government in East Asian Industrialization. Princeton: Princeton University Press.

Woo-cumings, M. (1999). The state, democracy, and the reform of the corporate sector in Korea. In: Pempel, T.J. (ed.). The Politics of the Asian Economic Crisis. New York: Cornell University Press, p. 116-142. 